\title{
Consequences of Severe lodine Deficiency in Pregnancy: Evidence in Humans
}

\author{
Freddy J. K. Toloza ${ }^{1,2}$, Hooman Motahari ${ }^{1}$ and Spyridoula Maraka ${ }^{1,2,3 *}$ \\ ${ }^{1}$ Division of Endocrinology and Metabolism, University of Arkansas for Medical Sciences, Little Rock, AR, United States, \\ ${ }^{2}$ Division of Endocrinology, Diabetes, Metabolism and Nutrition, Department of Medicine, Mayo Clinic, Knowledge and \\ Evaluation Research Unit in Endocrinology (KER-Endo), Rochester, MN, United States, ${ }^{3}$ Central Arkansas Veterans \\ Healthcare System, Little Rock, AR, United States
}

\section{OPEN ACCESS}

Edited by: Elizabeth Pearce,

Boston University, United States

Reviewed by:

Creswell John Eastman, Westmead Hospital, Australia Inés Velasco,

Andusian Health Service, Spain

*Correspondence: Spyridoula Maraka smaraka@uams.edu

Specialty section: This article was submitted to Thyroid Endocrinology,

a section of the journal Frontiers in Endocrinology

Received: 02 April 2020 Accepted: 21 May 2020

Published: 19 June 2020

Citation:

Toloza FJK, Motahari H and Maraka S (2020) Consequences of Severe lodine Deficiency in Pregnancy: Evidence in Humans.

Front. Endocrinol. 11:409. doi: 10.3389/fendo.2020.00409 lodine is a necessary micronutrient for the production of thyroid hormones and normal human development. Despite the significant worldwide strategies for the prevention and control of iodine deficiency, it is still a prevalent public health issue, especially in pregnant women. Severe iodine deficiency during pregnancy and neonatal period is associated with many major and irreversible adverse effects, including an increased risk of pregnancy loss and infant mortality, neonatal hypothyroidism, cretinism, and neuropsychomotor retardation. We will review the impact of severe iodine deficiency on maternofetal, neonatal, and offspring outcomes. We will also discuss its epidemiology, classification of iodine deficiency severity, and current recommendations to prevent iodine deficiency in childbearing age and pregnant women.

Keywords: iodine, pregnancy, deficiency, severe, thyroid

\section{INTRODUCTION}

Dietary iodine is an essential micronutrient for thyroid hormone synthesis, and adequate thyroid hormone production is required for normal human development (1). Consequently, sustained deficiency in iodine intake results in a reduction of thyroid hormone production and action, and herein significant adverse health effects, especially in pregnant women and their offspring (2). Additionally, it has been described that iodine has a central role in post-natal development and plasticity of neural tissues (3). As a result, iodine deficiency can affect fetal programming through imprinting of central nervous system cells and then exert postnatal effects (4). These adverse effects are driven through the role of thyroid hormones [thyroxine (T4) and tri-iodothyronine (T3)] in neurological development, as they are required for normal neuronal migration, myelination, and synaptic transmission and plasticity during fetal and early post-natal life $(5,6)$. Therefore, iodine deficiency during pregnancy has been noted as the most significant preventable cause of brain damage since the beginning of the nineteenth century and enormous global strategies to eradicate this public health problem have been issued (7).

Severe iodine deficiency (SID) during pregnancy and neonatal period is associated with many other major and irreversible adverse effects, including an increased risk of pregnancy loss and infant mortality, neonatal hypothyroidism, cretinism, and neuropsychomotor retardation $(8,9)$. Currently, despite the significant worldwide strategies for the prevention and control of iodine deficiency, it is still a prevalent public health issue, especially in pregnant women (10-12). In this article, we provide an overview of the epidemiology of SID during pregnancy and its consequences on maternofetal, neonatal, and offspring outcomes. 


\section{CLASSIFICATION OF IODINE DEFICIENCY SEVERITY}

The median urinary iodine concentration (UIC) is the recommended test by the World Health Organization (WHO) for assessing iodine intake status in populations. Because $>90 \%$ of iodine intake is excreted in the urine, UIC is an excellent measure of recent iodine intake $(7,13)$. When the median UIC of school-age children is $<20 \mu \mathrm{g} / \mathrm{L}$, a population is considered to have SID, and when it has values of $20-99 \mu \mathrm{g} / \mathrm{L}$, a population is considered mildly to moderately iodine deficient (14). As there is a limited number of studies assessing the iodine status in pregnant women, the median UIC of school-age children has been comparatively used, although it may not be representative of the iodine status of pregnant women in the same regions (15). This discrepancy could be due to differences in body size, urinary volumes, renal function (glomerular filtrate rate), and iodine requirements during pregnancy $(9,16)$.

In 2007, an updated epidemiological criterion for pregnant women's iodine nutrition status was established by consensus/committee decision of a Technical Consultation of the WHO (17). This new criterion recommended a population median UIC cut-off of $<150 \mu \mathrm{g} / \mathrm{L}$ for defining iodine insufficiency in any trimester of pregnancy (7). This cut-off is $50 \mu \mathrm{g} / \mathrm{L}$ above the median UIC threshold in school-age children and adults, reflecting the higher iodine demand and intake recommendations in pregnancy (18). However, there are still no proposed cut-offs for the severity of iodine deficiency in pregnancy (7). Thus, for research purposes usually it is assumed that the severity of iodine deficiency in pregnant women is defined similarly to children and it is corresponding to the severity of iodine deficiency observed in children and adults living in the same region (19).

\section{EPIDEMIOLOGICAL ASPECTS}

Historically iodine deficiency was thought to be more likely found in mountainous regions and areas exposed to frequent flooding (20). However, available data worldwide over the past two decades show that iodine deficiency is not restricted to those areas, and has been reported in different places around the world, including industrialized countries (21). As a result, universal strategies have been recommended to mitigate this global health issue. In the early nineties, the World Health Assembly set up the goal of eliminating iodine deficiency worldwide, and the UNICEF-WHO joint committee identified and recommended the strategy of universal salt iodization to prevent iodine deficiency disorders (22).

While complete eradication of iodine deficiency has not yet been reached, there has been a recognizable reduction

Abbreviations: ALSPAC, avon longitudinal study of parents and children; $\mathrm{CI}$, confidence interval; HR, hazard ratio; IQ, intelligence quotient; NHANES, National Health and Nutrition Examination Survey; OR, odds ratio; RCT, randomized clinical trial; RR, relative risk; SID, severe iodine deficiency; T3, triiodothyronine; T4, thyroxine; TSH, thyroid-stimulating hormone; UIC, urinary iodine concentration; US, United States; WHO, World Health Organization. in iodine-deficient areas, and according to recent data, more than $70 \%$ of households consume sufficient amount of iodized salt $(7,23)$. Nonetheless, iodine deficiency is still a prevalent problem, particularly during pregnancy. The most recent data of the US National Health and Nutrition Examination Survey (NHANES) 2005-2010 showed that the median UIC of pregnant participants in the US was $129 \mu \mathrm{g} / \mathrm{L}$, suggesting an insufficient iodine status (24). In Europe, according to a 2015 estimate, women in approximately two-thirds of countries with available data were iodine deficient during pregnancy (25). In 2017, the Iodine Global Network published the Global Scorecard of Iodine Nutrition, which reported as insufficient the iodine intakes of pregnant women from more than half of the included countries (26).

Additionally, a recent systematic review of 13 studies from different regions of the world, including 14,042 pregnant women showed that the prevalence of insufficient iodine status ranged from 16.1 to $84.0 \%$, and the median of iodine intake was insufficient in $75 \%$ of the studies (20). However, as there is no classification for mild, moderate, or severe iodine deficiency in pregnant women, it is difficult to portray the severity of this problem. Table 1 summarizes the available evidence regarding the epidemiology of SID in pregnant and childbearing age women (10-12, 27-34) using the severity classification for the general population.

\section{MATERNOFETAL CONSEQUENCES}

During pregnancy, there is an increase in iodine demand and thyroid hormone production due to several factors, including increased human chorionic gonadotropin level, higher levels of circulating estrogens that result in a progressive increase in thyroxine-binding globulin levels, presence of type 2 and type 3 deiodinases in the placenta, and increased maternal renal iodine excretion $(1,35,36)$. Therefore, adequate iodine intake in pregnancy is crucial for maternal health and optimal fetal development. Since the beginning of the embryonic stage to mid-gestation (20 weeks), the fetus is entirely dependent on the maternal thyroid hormones and iodine supply (5). Maternal T4 is converted through placental deiodination into T3, and T3 acts in peripheral tissues playing an important role in fetal neurodevelopment (5). Specifically, T3 binds to its receptor in cells of the central nervous system and activates the transcription and expression of genes involved in axonal and dendrite outgrowth, cell migration, synapse formation and myelination $(4,37,38)$. Thus, fetal development is dependent on adequate thyroid hormone, and SID is associated with serious and irreversible fetal and offspring damages.

Moreover, SID is associated with adverse pregnancy outcomes, including miscarriage, stillbirth, neonatal mortality, and growth retardation (Table 2). The first report of the association between iodine deficiency and stillbirth/abortion was published by Kemp in 1,939 (42). Another study, including 4,980 women of West Africa, reported that among women with SID, there was an increased risk of reproductive failure (stillbirths or recurrent miscarriages) $[\mathrm{OR}=3.64 ; 95 \% \mathrm{CI} 2.92-4.55]$ compared to the 
TABLE 1 | Epidemiology of severe iodine deficiency in pregnant and childbearing age women.

\begin{tabular}{|c|c|c|c|c|c|c|c|}
\hline First author & Year & Country & $n$ & Population & Median UIC ( $\mu \mathrm{g} / \mathrm{L})$ & $\begin{array}{l}\text { SID cutoff } \\
(\mu \mathrm{g} / \mathrm{L})\end{array}$ & $\begin{array}{l}\text { Patients with } \\
\text { SID (\%) }\end{array}$ \\
\hline Dillon and Milliez (27) & 2000 & Senegal & 4,980 & $\begin{array}{l}\text { Childbearing age women } \\
\text { (Pregnant women: 462) }\end{array}$ & 43.0 & $<20$ & 22.7 \\
\hline Konrade et al. (10) & 2015 & Latvia & 829 & Pregnant women & 80.8 [IQR 46.1-130.6] ${ }^{\star}$ & $<20^{*}$ & 4.5 \\
\hline Kurtoglu et al. (28) & 2004 & Turkey & 70 & Pregnant women & 30.2 & $<20$ & 33.0 \\
\hline Markhus et al. (11) & 2018 & Norway & 851 & Pregnant women & 78.0 [IQR 46.0-130.0] & $<20$ & 7.3 \\
\hline Mills et al. (29) & 2018 & USA & 501 & $\begin{array}{l}\text { Childbearing age women } \\
\text { planning a pregnancy }\end{array}$ & 112.8 [IQR 53.6-216.9] & $<20$ & 1.7 \\
\hline Ovadia et al. (30) & 2017 & Israel & 1,074 & Pregnant women & 61.0 [IQR 36.0-97.0] & $<30$ & 29.0 \\
\hline Robinson et al. (31) & 2018 & United Kingdom & 654 & $\begin{array}{l}\text { Childbearing age women } \\
\text { planning a pregnancy }\end{array}$ & 108.4 [IQR 62.2-167.8] & $<20$ & 2.5 \\
\hline Sekitani et al. (32) & 2013 & Ukraine & 148 & Pregnant women & $13.0^{\S}$ & $<25$ & 50.0 \\
\hline Simpong et al. (12) & 2016 & Ghana & 120 & Pregnant women & NA & $<20$ & 11.7 \\
\hline Stinca et al. (33) & 2017 & Morocco & 640 & $\begin{array}{l}\text { Childbearing age women: } 156 \\
\text { Pregnant women: } 245 \\
\text { Lactating women: } 239\end{array}$ & $\begin{array}{l}41.0 \text { [IQR 29.0-63.0] } \\
35.0 \text { [IQR 19.0-62.0] } \\
32.0 \text { [IQR 17.0-58.0] }\end{array}$ & $\begin{array}{l}<20 \\
\text { NA } \\
<20\end{array}$ & $\begin{array}{l}8.0 \\
\text { NA } \\
28.0\end{array}$ \\
\hline Wang et al. (34) & 2009 & China & 1,751 & $\begin{array}{l}\text { Pregnant women: } 487 \\
\text { Lactating women: } 1,264\end{array}$ & $\begin{array}{l}172.2 \\
159.2\end{array}$ & $<20$ & $\begin{array}{l}2.5 \\
3.4\end{array}$ \\
\hline
\end{tabular}

Not available (NA), Interquartile range (IQR), Urinary iodine concentration (UIC), Severe iodine deficiency (SID).

${ }^{*}$ Creatinine-standardized urinary iodine concentration, § Mean value.

group with iodine sufficiency (27). However, this study has important limitations, such as self-reported past medical history and adverse pregnancy outcomes. In 1975, Pharoah et al. (43) conducted a randomized clinical trial (RCT) in the highlands of New Guinea, which found that iodine supplementation during pregnancy decreased the incidence of stillbirths and infant mortality.

Similarly, a prospective cohort study published in 2018 showed that among 2,347 pregnant women, participants with iodine sufficiency (UIC 150-249 $\mu \mathrm{g} / \mathrm{L}$ ) had decreased rates of preeclampsia [adjusted OR $=0.12 ; 95 \%$ CI $0.01-0.87$ ], placenta previa [adjusted OR $=0.06 ; 95 \% \mathrm{CI} 0.01-0.69$ ], and fetal distress [adjusted OR $=0.10 ; 95 \% \mathrm{CI} 0.02-0.64$ ] compared with participants with SID (UIC $<50 \mu \mathrm{g} / \mathrm{L}$ ) (41). In a Hispanic population $(n=239)$, pregnant women with mild iodine deficiency had a lower risk of having a small for gestational age newborn compared with those women with UIC $<50 \mu \mathrm{g} / \mathrm{L}$ [adjusted OR $=0.15$; 95\%CI 0.03-0.76] (39). Nevertheless, it is necessary to consider specific limitations of these studies, including relatively small sample sizes with inadequate power to assess differences in rare outcomes, samples' collection at variables gestational ages, and lack of consideration of thyroid autoimmunity as a critical factor in pregnancy outcomes. Finally, treating pregnant women with oral iodized oil just before conception or during the first trimester significantly increased placental and birth weights in a region of endemic goiter area in Algeria (44). The same study reported that in the treated group the rates of abortion (0\%), prematurity (10.8\%) and stillbirth (9.0\%) were significantly lower than in the untreated group (19.0, 14.3 , and $20.4 \%$, respectively) ( $p<0.001$ for all) (44).

In contrast to these findings, some recent evidence has shown that there is no association of SID with some adverse maternofetal outcomes. In a population-based cohort study including 329 pregnant women, the risk of pregnancy loss was not elevated in the severely deficient group [defined as UIC $<50 \mu \mathrm{g} / \mathrm{L}](\mathrm{HR}=0.69 ; 95 \% \mathrm{CI} 0.32-1.50)$ compared to the iodine sufficient group (29). Torlinska et al. (40) used data from 3,140 singleton pregnancies of the Avon Longitudinal Study of Parents and Children (ALSPAC) to assess whether iodine deficiency during pregnancy was associated with adverse pregnancy outcomes. They reported that the incidence of preeclampsia, non-proteinuric gestational hypertension, gestational diabetes, glycosuria, anemia, postpartum hemorrhage, being small for gestational age, mode of delivery, preterm delivery, and large for gestational age was not significantly different among severely iodine deficient pregnant women (UIC/Creat $<50 \mu \mathrm{g} / \mathrm{g}$ ) compared to the iodine sufficient group (40). However, given the low number of adverse pregnancy outcomes in these studies, it is possible that they were underpowered to detect the effects of SID during pregnancy. In addition, it may suggest that different confounding factors associated with SID could be at play in influencing obstetric outcomes in different settings (40).

Finally, another frequently attributed impact of SID before and during pregnancy is the induction of maternal hypothyroxinemia $(6,45)$. Although there is no direct evidence supporting the role of iodine deficiency as a cause of maternal or fetal hypothyroxinemia in humans, this has been suggested by a few clinical studies showing that iodine supplementation during pregnancy reduces the risk of maternal hypothyroxinemia (4648). Hypothyroxinemia is defined by free T4 levels significantly below those considered ideal for a given gestational age. In such cases, the low free T4 levels lead to increased thyroidal stimulation via the pituitary feedback mechanisms (TSH secretion) and, ultimately to goiter formation in both the mother 
TABLE 2 | Studies investigating the effect of severe iodine deficiency on pregnancy outcomes.

\begin{tabular}{|c|c|c|c|c|}
\hline First author & Year & Country & $n$ & Design \\
\hline $\begin{array}{l}\text { Alvarez- } \\
\text { Pedrerol et al. } \\
\text { (39) }\end{array}$ & 2009 & Spain & 657 & $\begin{array}{l}\text { Prospective study conducted } \\
\text { on pregnant women. The } \\
\text { association between thyroid } \\
\text { hormones and UIC during the } \\
\text { first and third trimesters, and } \\
\text { birth weight was studied. }\end{array}$ \\
\hline
\end{tabular}

Dillon and Milliez (27)

2000 Senegal

4,980 Epidemiological survey on carried out in 1996-1997. Childbearing age women were questioned about their obstetric histories, including the numbers of miscarriages and stillbirths. Urine samples were collected, the iodine level measured.

Mills et al. (29) 2018 USA

501 Population-based prospective cohort study, monitored women who had discontinued contraception within 2 months to become pregnant; 329 became pregnant; had UIC measured on samples collected at enrollment, and were followed up to determine pregnancy outcomes.

Torlinska et al. 2018 United Kingdom 3,140 Prospective study using data 61.0 (40)

Yang (41) 2018 China
Study of Parents and Children (ALSPAC). This study assessed whether iodine deficiency during pregnancy was associated with pregnancy/infant loss, or with other adverse pregnancy outcomes. iodine deficiency disorders

\section{Median UIC Outcomes assessed}

( $\mu \mathrm{g} / \mathrm{L})$

\section{1st trimester: $\quad 1$ st trimester}

95.0 3rd lodine sufficiency (UIC 150-249 $\mu \mathrm{g} / \mathrm{L})$ vS. SID (UIC <50 $\mu \mathrm{g} / \mathrm{L})$

trimester: 104.0 - Small for gestational age: OR $1.34(95 \% \mathrm{Cl}$ 0.16-12.06) 1st trimester

Mild iodine deficiency (UIC 100-149 $\mu \mathrm{g} / \mathrm{L}) \mathrm{vs}$. SID (UIC <50 $<\mathrm{g} / \mathrm{L})$

- Small for gestational age: OR 0.37 (95\%Cl 0.03-5.36)

3rd trimester

lodine sufficiency (UIC 150-249 $\mu \mathrm{g} / \mathrm{L})$ vs. SID (UIC $<50 \mu \mathrm{g} / \mathrm{L})$

- Small for gestational age: OR 0.37 (95\%Cl 0.10-1.40) 3rd trimester

Mild iodine deficiency (UIC 100-149 $\mu \mathrm{g} / \mathrm{L})$ vs. SID (UIC $<50 \mu \mathrm{g} / \mathrm{L})$

- Small for gestational age: OR $0.15(95 \% \mathrm{Cl} 0.03-0.76)^{*}$

$43.0 \quad \mathrm{SID}(\mathrm{UIC}<20 \mu \mathrm{g} / \mathrm{L}) \mathrm{vs}$. Iodine sufficiency (UIC 101-150 $\mu \mathrm{g} / \mathrm{L})$

- Reproductive failure: OR $3.64(95 \% \mathrm{Cl} 2.92-4.55)^{\star}$

SID (UIC <50 $\mu \mathrm{g} / \mathrm{L})$ vs. lodine sufficiency (UIC 150-249 $\mu \mathrm{g} / \mathrm{L})$ - Pregnancy loss: HR 0.69 (95\%Cl 0.32-1.50)

$\mathrm{SID}(\mathrm{UIC}<50 \mu \mathrm{g} / \mathrm{L})$ vs. lodine sufficiency (UIC 150-249 $\mu \mathrm{g} / \mathrm{L})$

- Hypertensive disorders of pregnancy: OR 1.2 (95\%Cl 0.7-1.9)

- Preeclampsia: OR 0.6 (95\%Cl 0.1-3.1)

- Non-proteinuric gestational hypertension: OR 1.2 (95\%Cl 0.7-2.1)

- Any glucose derangement: OR 1.1 (95\%Cl 0.5-2.3)

- Gestational diabetes: OR $1.6(95 \% \mathrm{Cl} 0.2-17.1)$

- Glycosuria: OR 0.7 (95\%Cl 0.2-2.0)

- Hyperglycemia during pregnancy: OR 1.0 (95\%Cl 0.5-2.4)

- Anemia during pregnancy: OR 1.2 (95\% Cl 0.5-2.5)

- Anemia < 14 days postpartum: OR 0.6 (95\%Cl 0.3-1.1)

- Postpartum hemorrhage: OR 1.2 (95\%Cl 0.6-2.3)

- Preterm delivery: OR 1.3 (95\%Cl 0.6-3.0)

- Cesarean section: OR $0.6(95 \% \mathrm{Cl} 0.3-1.3)$

- Assisted/breech delivery: OR 1.2 (95\%Cl 0.7-2.3)

- Small for gestational age: OR 1.5 (95\%Cl 0.7-3.1)

- Large for gestational age: OR 0.7 (95\%Cl 0.2-1.8)

lodine sufficiency (UIC 150-249 $\mu \mathrm{g} / \mathrm{L})$ vs. SID (UIC $<50 \mu \mathrm{g} / \mathrm{L})$

- Cesarean delivery: OR 0.78 (95\%Cl 0.50-1.21)

- Preterm delivery: OR 1.38 (95\% Cl 0.32-6.01)

- Gestational diabetes: OR 0.32 (95\%Cl 0.03-3.23)

- Preeclampsia: OR 0.12 (95\%Cl 0.01-0.87)

- Gestational hypertension: OR 0.49 (95\%Cl 0.13-1.89)

- Placenta previa: OR $0.06(95 \% \mathrm{Cl} 0.01-0.69)^{*}$

- Abnormal amniotic fluid: OR 0.51 (95\%Cl 0.22-1.20)

- Fetal distress: OR $0.10(95 \% \mathrm{Cl} 0.02-0.64)^{\star}$

- Umbilical cord entanglement: OR 0.55 (95\%Cl 0.22-1.38)

- Low birth weight: OR 3.73 (95\%Cl 0.69-20.28)

- Macrosomia: OR 1.19 (95\%Cl 0.53-2.69)

- Small for gestational age: OR $0.89(95 \% \mathrm{Cl} 0.45-1.78)$

Urinary iodine concentration (UIC), Severe iodine deficiency (SID), Odds ratio (OR), Hazard ratio (HR), Confidence interval (CI).

*Statistically significant difference between groups. 
and fetus. In areas of SID, increased rates of goiter and thyroid nodules during pregnancy have been reported (49-51) and the supplementation of iodine has been associated with reduction of maternal thyroid size (52).

\section{NEONATAL AND OFFSPRING CONSEQUENCES}

SID and its treatment also affect neonatal/infant anthropometric parameters, thyroid function, nutritional status, and mortality. In a severely iodine-deficient area of western China, iodine supplementation in 295 pregnant women increased head circumference and reduced the rate of microcephaly from 27 to $11 \%(p=0.006)(53)$. Treatment with iodized oil before conception or during pregnancy resulted in higher birth weights compared with the offspring of untreated mothers in Zaire $(+3.7 \%)$ (54) and Algeria (+6.3\%) (44). In a large Asian study, the use of iodized salt during pregnancy correlated with increased weight for age and an increased mid-upper-arm circumference during infancy (55). However, it is possible that pregnant women with adequate iodine intake had a better socioeconomic and nutritional status, which might have resulted in better anthropometric indices in their offspring. Ultrasonographic measurements of thyroid volume in neonates showed that thyroid sizes were $40 \%$ larger in the newborns from non-supplemented mothers compared with newborns from iodine-supplemented mothers. Moreover, glandular hyperplasia was already present in $10 \%$ of these neonates, compared with none in the group whose mothers received iodine $(45,56)$.

Neonatal and infant survival rates improved in infants born to women whose iodine deficiency was corrected before or during pregnancy. Delong et al. (57) added potassium iodate to irrigation water in three areas with SID in China and found a significant reduction in neonatal and infant mortality in these areas after 2-3 years compared with areas that did not receive iodine. In Zaire, the supplementation of iodized oil intramuscularly to severely iodine deficient pregnant women at 28 weeks of gestation significantly decreased infant mortality rate compared to the untreated group (113/1000 vs. $243 / 1000)$ (58). In a large crosssectional study, the use of adequately iodized salt in a severely deficient area in Indonesia was associated with a significantly lower prevalence of child malnutrition and mortality in neonates, infants, and children aged $<5$ years $(59,60)$. Nevertheless, the findings of this study carry a risk of misclassification, as the adequacy of iodized salt was assessed with a rapid test, and its sensitivity and specificity were not tested against the iodometric titration method (gold standard). Another trial from Pharoah et al. (61) evaluated the effect of a single intramuscular injection of either iodized oil or saline solution on neonatal mortality. They showed that neonatal mortality rates were lower in the iodized oil-injected group (13.3\%) than in the untreated group (18.2\%).

When severe enough, iodine deficiency induces fetal hypothyroxinemia. Any degree of thyroid hormone unavailability during critical periods of brain development may produce irreversible brain damage, and consequently, neurocognitive delay and neurological abnormalities of the offspring $(5,45,61)$. The extent of these consequences depends upon the timing and severity of the hypothyroxinemia. The most severe manifestation of in utero iodine deficiency is cretinism, which has been described in two forms: neurological and myxedematous (hypothyroid) (62). Approximately 4\%-10\% of pregnant women who are severely iodine deficient give birth to a child with cretinism $(54,58,63,64)$. Neurological cretinism is the most common form, and its clinical features include neurocognitive delay, hearing and speech defects (deaf-muteness of varying degree), squint, impaired voluntary motor activity (spastic diplegia or paresis of the lower limbs), and stance disorders (spastic gait and ataxia) $(62,65,66)$. Myxedematous cretinism is characterized by severe or longstanding hypothyroidism with the following features: myxedema, dwarfism, delayed maturation of body parts, skeletal retardation, dry, thickened skin, sparseness of hair and nails, sexual retardation, deep hoarse voice, delayed tendon reflexes, and poor bowel function $(62,65,66)$. Although some degree of goiter might be expected in children with myxedematous cretinism, conversely, thyroid atrophy appears to be a common finding (65). Despite the fact that these types of cretinism have distinct clinical manifestations, it has been described that both types share some neurological features, including neurocognitive delay, pyramidal/extrapyramidal dysfunction, deafness, and primitive reflexes $(65,66)$. Therefore, the two forms of cretinism might be part of a spectrum of diffuse insult to the developing fetal nervous system, where post-natal thyroid hormone deficiency, in the case of myxedematous cretinism, may result in their characteristic manifestations $(65,66)$.

The evidence linking SID to cretinism comes from landmark trials of iodine repletion during pregnancy in areas with SID in Papua New Guinea (61) and Zaire (54). In these trials, iodine supplementation using iodized oil was associated with a significant reduction in the prevalence of endemic cretinism at 4 years $[\mathrm{RR}=0.27 ; 95 \% \mathrm{CI} 0.12-0.60]$ and at 10 years of age $[R R=0.17 ; 95 \% C I 0.05,0.58]$ (53) and with higher psychomotor development scores at 72 months in the offspring of iodine-treated mothers (91 \pm 13 vs. $82 \pm 14$ in the controls) (54). Cao et al. (53) published a study in an area of SID and endemic cretinism in western China, including groups of children from birth to 3 years $(n=689)$ and women at each trimester of pregnancy $(n=295)$ (53). The intervention was oral iodized oil, and participants were followed for 2 years. The prevalence of moderate/severe neurological abnormalities among the offspring of those mothers who received iodine in the first or second trimester was $2 \%$, compared with $9 \%$ among the infants whose mothers received iodine during the third trimester or after birth. The prevalence of microcephaly was higher in the untreated group compared with the treated group, and the mean developmental quotient at 2 years of age was higher in the treated than in the untreated children (90 \pm 14 vs. $75 \pm 18$ ) (53). In a follow-up study of the same population, school-age children of the women treated before the end of their second trimester achieved higher psychomotor scores than those from mothers treated in the third trimester ( 86.2 vs. $81.5 ; p=0.02$ ), but no 
differences in psychological or language development tests were found (67). However, this study used tests that may not have been entirely appropriate for a population of children of that age. These data suggested that iodine supplementation before the beginning of the third trimester might reduce the negative influences of SID on the nervous system, while later intervention could not reverse the impairment of neurological status.

Trials in Peru and Ecuador also demonstrated benefits in the rates of cretinism and neurodevelopment with the use of iodized oil during pregnancy $(63,64)$. In Peru, women of childbearing age from Andean villages in an area of SID received either iodized oil injection or nothing, and cognitive development scores of their offspring were assessed between 1 and 4 years of age (63). Initially, there was no statistical difference in cognitive outcomes between groups; however, when children's iodine status was evaluated, there was a significantly higher intelligence quotient (IQ) score in the iodine-sufficient group compared with the iodine-deficient group (85.6 \pm 13.9 vs. $74.4 \pm 4.8$ ) (63). Fierro-Benitez et al. (64) studied two villages with severe intellectual disability and cretinism rates in Ecuador. One village received an injection of iodized oil, whereas the other was not treated. Both villages were followed at 4-year intervals for 20 years, and the neurocognitive effects on the offspring were recorded. Mean IQ measured in first and second grade children was higher in the treated village than in the control village. Five years after the beginning of the trial, the treated group was stratified according to the period when iodine was initiated. The group of children whose mothers had received iodine before conception had significantly higher IQ than the group of children born after treatment had begun or the group whose mothers received iodine during pregnancy (76.8 vs. 72.3 vs. 65.2 , respectively) (64). However, it is relevant to highlight that this study evaluated only the school performance of children enrolled in elementary school, who had completed at least 1 year of education. Therefore, these findings do not reflect the effect of inadequate iodine intake during pregnancy on the group of children that were not enrolled in elementary school or quitted during their first year of education.

In 2005, a meta-analysis aimed to summarize the evidence regarding the effects of iodine on the intellectual development of Chinese children showed a profound intelligence deficit in children exposed to SID, with a loss of 12.45 IQ points. With an adequate iodine supplementation for mothers before and during gestation, the IQ of their children was increased by 8.7 points (68). Additionally, studies in the Chinese population several decades ago showed that people born and continuing to live in regions of iodine deficiency, even if it is moderate deficiency, had impaired intellectual and neuromotor manifestations across a broad spectrum of severity (60-62, $65,69,70)$. Thus, this evidence highlights the importance of

\section{REFERENCES}

1. Glinoer D. The regulation of thyroid function in pregnancy: pathways of endocrine adaptation from physiology to pathology. Endocr Rev. (1997) 18:404-33. doi: 10.1210/edrv.18. 3.0300 iodine supplementation during the neonatal period and infancy, primarily through its supplementation in breastfeeding mothers, as direct supplementation of iodine in neonates has been shown to be less effective in improving infant iodine status (71).

\section{CURRENT RECOMMENDATIONS}

As many studies have established the consequences of SID and the benefits of iodine supplementation during pregnancy, there are specific recommendations to prevent iodine deficiency in childbearing age and pregnant women. In 2007, the WHO and International Council for Control of Iodine Deficiency Disorders guidelines suggested an iodine intake of 200-300 $\mu \mathrm{g} /$ day for pregnant and lactating women (7). Similarly, the Endocrine Society guidelines (72) recommended that women of childbearing age should have an average iodine intake of $150 \mu \mathrm{g} /$ day, and it should be increased to $250 \mu \mathrm{g} /$ day during pregnancy and breastfeeding. The same guideline also recommends the use of once-daily prenatal vitamins containing 150-200 $\mu \mathrm{g}$ iodine before conception and during pregnancy. The most recent guidelines issued by the American Thyroid Association (73) suggested that all pregnant women should ingest $\sim 250 \mu \mathrm{g}$ iodine daily, and women who are planning pregnancy or are currently pregnant, should add to their diet a daily oral supplement that contains $150 \mu \mathrm{g}$ of iodine. The above guideline also recommends that in low-resource countries and regions where salt iodization or daily iodine supplements are not feasible, a single annual dose of $400 \mathrm{mg}$ of iodized oil for pregnant women and women of childbearing age can be utilized as a temporary measure. Despite some discrepancies in these guidelines, in general, there is an agreement in the need to increase iodine intake during pregnancy, and in the use of daily iodine supplements before conception, during pregnancy, and lactation.

\section{CONCLUSION}

Adequate iodine status is essential for maternal and fetal health. SID during pregnancy results in irreversible, detrimental maternofetal and offspring effects. Considering the increased requirements for iodine intake during pregnancy, supplementation, even before conception, is recommended.

\section{AUTHOR CONTRIBUTIONS}

FT, HM, and SM have made a substantial, direct and intellectual contribution to the work, and approved it for publication. All authors contributed to the article and approved the submitted version. 
4. Velasco I, Bath SC, Rayman MP. Iodine as essential nutrient during the first 1000 days of life. Nutrients. (2018) 10:290. doi: 10.3390/nu10030290

5. Morreale de Escobar G, Obregon MJ, Escobar del Rey F. Role of thyroid hormone during early brain development. Eur J Endocrinol. (2004) 151(Suppl. 3):U25-37. doi: 10.1530/eje.0.151u025

6. Zimmermann MB. Iodine deficiency in pregnancy and the effects of maternal iodine supplementation on the offspring: a review. Am J Clin Nutr. (2009) 89:668S-72S. doi: 10.3945/ajen.2008.26811C

7. WHO, UNICEF, ICCIDD. Assessment of Iodine Deficiency Disorders and Monitoring Their Elimination: WHO. (2007). Available online at: https:// apps.who.int/iris/bitstream/handle/10665/43781/9789241595827_eng.pdf; jsessionid=931B8D22DC1C7DF093B0044F0FC7F983? sequence $=1$ (accessed February 22, 2020).

8. Zimmermann MB. Iodine deficiency. Endocr Rev. (2009) 30:376-408. doi: 10.1210/er.2009-0011

9. Pearce EN, Lazarus JH, Moreno-Reyes R, Zimmermann MB. Consequences of iodine deficiency and excess in pregnant women: an overview of current knowns and unknowns. Am J Clin Nutr. (2016) 104(Suppl. 3):918S-23S. doi: 10.3945/ajcn.115.110429

10. Konrade I, Kalere I, Strele I, Makrecka-Kuka M, Jekabsone A, Tetere E, et al. Iodine deficiency during pregnancy: a national crosssectional survey in Latvia. Public Health Nutr. (2015) 18:2990-7. doi: $10.1017 /$ S1368980015000464

11. Markhus MW, Dahl L, Moe V, Abel MH, Brantsaeter AL, Oyen J, et al. Maternal iodine status is associated with offspring language skills in infancy and toddlerhood. Nutrients. (2018) 10:1270. doi: 10.3390/nu100 91270

12. Simpong DL, Adu P, Bashiru R, Morna MT, Yeboah FA, Akakpo K, et al. Assessment of iodine status among pregnant women in a rural community in ghana - a cross sectional study. Arch Public Health. (2016) 74:8. doi: 10.1186/s13690-016-0119-y

13. Zimmermann MB. The Importance of adequate iodine during pregnancy and infancy. World Rev Nutr Diet. (2016) 115:118-24. doi: 10.1159/000442078

14. WHO. Vitamin and Mineral Nutrition Information System. Urinary Iodine Concentrations for Determining Iodine Status in Populations. (2016). Available online at: https://apps.who.int/iris/bitstream/handle/10665/85972/ WHO_NMH_NHD_EPG_13.1_eng.pdf?sequence=1 (accessed February 22, 2020).

15. Wong EM, Sullivan KM, Perrine CG, Rogers LM, Pena-Rosas JP. Comparison of median urinary iodine concentration as an indicator of iodine status among pregnant women, school-age children, and nonpregnant women. Food Nutr Bull. (2011) 32:206-12. doi: 10.1177/156482651103200304

16. Perrine CG, Sullivan KM, Flores R, Caldwell KL, Grummer-Strawn LM. Intakes of dairy products and dietary supplements are positively associated with iodine status among U.S. children. J Nutr. (2013) 143:1155-60. doi: $10.3945 /$ jn. 113.176289

17. Secretariat WHO, Andersson M, de Benoist B, Delange F, Zupan J. Prevention and control of iodine deficiency in pregnant and lactating women and in children less than 2-years-old: conclusions and recommendations of the Technical Consultation. Public Health Nutr. (2007) 10:1606-11. doi: $10.1017 /$ S1368980007361004

18. Bath SC. The effect of iodine deficiency during pregnancy on child development. Proc Nutr Soc. (2019) 78:150-60. doi: 10.1017/S002966 5118002835

19. Skeaff SA. Iodine deficiency in pregnancy: the effect on neurodevelopment in the child. Nutrients. (2011) 3:265-73. doi: 10.3390/nu3020265

20. Candido AC, Morais NS, Dutra LV, Pinto CA, Franceschini S, Alfenas RCG. Insufficient iodine intake in pregnant women in different regions of the world: a systematic review. Arch Endocrinol Metab. (2019) 63:306-11. doi: 10.20945/2359-3997000000151

21. Rayman MP, Bath SC. The new emergence of iodine deficiency in the UK: consequences for child neurodevelopment. Ann Clin Biochem. (2015) 52(Pt 6):705-8. doi: 10.1177/0004563215597249

22. UNICEF, WHO. WORLD SUMMIT FOR CHILDREN - MID-DECADE GOAL: IODINE DEFICIENCY DISORDERS (IDD). (1994). Available online at: http://www.ceecis.org/iodine/01_global/01_pl/01_01_1994_summit.pdf (accessed February 22, 2020).
23. UNICEF. The State of the World's Children 2012: Children in an Urban World. (2012). Available online at: https://www.unicef.org/sowc2012/pdfs/SOWC2012-Main-Report_EN_21Dec2011.pdf (accessed February 22, 2020).

24. Caldwell KL, Pan Y, Mortensen ME, Makhmudov A, Merrill L, Moye J. Iodine status in pregnant women in the National Children's Study and in U.S. women (15-44 years), National Health and Nutrition Examination Survey 2005-2010. Thyroid. (2013) 23:927-37. doi: 10.1089/thy.2013.0012

25. Zimmermann MB, Gizak M, Abbott K, Andersson M, Lazarus JH. Iodine deficiency in pregnant women in Europe. Lancet Diabetes Endocrinol. (2015) 3:672-4. doi: 10.1016/S2213-8587(15)00263-6

26. IGN. Global Scorecard 2016: Moving Toward Optimal Iodine Status. (2016). Available online at: http://www.ign.org/newsletter/idd_nov16_global_ scorecard_2016.pdf (accessed February 22, 2020).

27. Dillon JC, Milliez J. Reproductive failure in women living in iodine deficient areas of West Africa. BJOG. (2000) 107:631-6. doi: 10.1111/j.1471-0528.2000.tb13305.x

28. Kurtoglu S, Akcakus M, Kocaoglu C, Gunes T, Karakucuk I, Kula M, et al. Iodine deficiency in pregnant women and in their neonates in the central Anatolian region (Kayseri) of Turkey. Turk J Pediatr. (2004) 46:11-5.

29. Mills JL, Ali M, Buck Louis GM, Kannan K, Weck J, Wan Y, et al. Pregnancy loss and iodine status: the LIFE prospective cohort study. Nutrients. (2019) 11:534. doi: 10.3390/nu11030534

30. Ovadia YS, Arbelle JE, Gefel D, Brik H, Wolf T, Nadler V, et al. First israeli national iodine survey demonstrates iodine deficiency among school-aged children and pregnant women. Thyroid. (2017) 27:1083-91. doi: 10.1089/thy.2017.0251

31. Robinson SM, Crozier SR, Miles EA, Gale CR, Calder PC, Cooper C, et al. Preconception maternal iodine status is positively associated with IQ but not with measures of executive function in childhood. J Nutr. (2018) 148:959-66. doi: 10.1093/jn/nxy054

32. Sekitani Y, Hayashida N, Takahashi J, Kozlovsky AA, Rudnitskiy S, Petrova A, et al. Urinary iodine concentrations of pregnant women in Ukraine. Clin Chem Lab Med. (2013) 51:811-6. doi: 10.1515/cclm-2012-0397

33. Stinca S, Andersson M, Herter-Aeberli I, Chabaa L, Cherkaoui M, El Ansari $\mathrm{N}$, et al. Moderate-to-severe iodine deficiency in the "first 1000 days" causes more thyroid hypofunction in infants than in pregnant or lactating women. $J$ Nutr. (2017) 147:589-95. doi: 10.3945/jn.116.244665

34. Wang Y, Zhang Z, Ge P, Wang Y, Wang S. Iodine deficiency disorders after a decade of universal salt iodization in a severe iodine deficiency region in China. Indian J Med Res. (2009) 130:413-7.

35. Moleti M, Trimarchi F, Vermiglio F. Thyroid physiology in pregnancy. Endocr Pract. (2014) 20:589-96. doi: 10.4158/EP13341.RA

36. Davison JM, Dunlop W. Renal hemodynamics and tubular function normal human pregnancy. Kidney Int. (1980) 18:152-61. doi: 10.1038/ki.1980.124

37. Moog NK, Entringer S, Heim C, Wadhwa PD, Kathmann N, Buss C. Influence of maternal thyroid hormones during gestation on fetal brain development. Neuroscience. (2017) 342:68-100. doi: 10.1016/j.neuroscience.2015. 09.070

38. Mohan V, Sinha RA, Pathak A, Rastogi L, Kumar P, Pal A, et al. Maternal thyroid hormone deficiency affects the fetal neocorticogenesis by reducing the proliferating pool, rate of neurogenesis and indirect neurogenesis. Exp Neurol. (2012) 237:477-88. doi: 10.1016/j.expneurol.2012.07.019

39. Alvarez-Pedrerol M, Guxens M, Mendez M, Canet Y, Martorell R, Espada $\mathrm{M}$, et al. Iodine levels and thyroid hormones in healthy pregnant women and birth weight of their offspring. Eur J Endocrinol. (2009) 160:423-9. doi: 10.1530/EJE-08-0716

40. Torlinska B, Bath SC, Janjua A, Boelaert K, Chan SY. Iodine status during pregnancy in a region of mild-to-moderate iodine deficiency is not associated with adverse obstetric outcomes; results from the avon longitudinal study of parents and children (ALSPAC). Nutrients. (2018) 10:291. doi: 10.3390/nu10030291

41. Yang J, Liu Y, Liu H, Zheng H, Li X, Zhu L, et al. Associations of maternal iodine status and thyroid function with adverse pregnancy outcomes in Henan Province of China. J Trace Elem Med Biol. (2018) 47:104-10. doi: 10.1016/j.jtemb.2018.01.013

42. Kemp WN. Iodine deficiency in relation to the stillbirth problem. Can Med Assoc J. (1939) 41:356-61. 
43. Pharoah PO, Ellis SM, Ekins RP, Williams ES. Maternal thyroid function, iodine deficiency and fetal development. Clin Endocrinol. (1976) 5:159-66. doi: 10.1111/j.1365-2265.1976.tb02827.x

44. Chaouki ML, Benmiloud M. Prevention of iodine deficiency disorders by oral administration of lipiodol during pregnancy. Eur J Endocrinol. (1994) 130:547-51. doi: 10.1530/eje.0.1300547

45. Glinoer D. Clinical and biological consequences of iodine deficiency during pregnancy. Endocr Dev. (2007) 10:62-85. doi: 10.1159/000106820

46. Berbel P, Mestre JL, Santamaria A, Palazon I, Franco A, Graells M, et al. Delayed neurobehavioral development in children born to pregnant women with mild hypothyroxinemia during the first month of gestation: the importance of early iodine supplementation. Thyroid. (2009) 19:511-9. doi: 10.1089/thy.2008.0341

47. Moleti M, Lo Presti VP, Campolo MC, Mattina F, Galletti M, Mandolfino $\mathrm{M}$, et al. Iodine prophylaxis using iodized salt and risk of maternal thyroid failure in conditions of mild iodine deficiency. J Clin Endocrinol Metab. (2008) 93:2616-21. doi: 10.1210/jc.2008-0352

48. Moleti M, Di Bella B, Giorgianni G, Mancuso A, De Vivo A, Alibrandi $A$, et al. Maternal thyroid function in different conditions of iodine nutrition in pregnant women exposed to mild-moderate iodine deficiency: an observational study. Clin Endocrinol. (2011) 74:762-8. doi: 10.1111/j.1365-2265.2011.04007.x

49. Bauch K, Meng W, Ulrich FE, Grosse E, Kempe R, Schonemann F, et al. Thyroid status during pregnancy and post partum in regions of iodine deficiency and endemic goiter. Endocrinol Exp. (1986) 20:67-77.

50. Smyth PP, Hetherton AM, Smith DF, Radcliff M, O'Herlihy C. Maternal iodine status and thyroid volume during pregnancy: correlation with neonatal iodine intake. J Clin Endocrinol Metab. (1997) 82:2840-3. doi: 10.1210/jcem.82.9.4203

51. Sahin SB, Ogullar S, Ural UM, Ilkkilic K, Metin Y, Ayaz T. Alterations of thyroid volume and nodular size during and after pregnancy in a severe iodine-deficient area. Clin Endocrinol. (2014) 81:762-8. doi: $10.1111 /$ cen. 12490

52. Liesenkotter KP, Gopel W, Bogner U, Stach B, Gruters A. Earliest prevention of endemic goiter by iodine supplementation during pregnancy. Eur J Endocrinol. (1996) 134:443-8. doi: 10.1530/eje.0.1340443

53. Cao XY, Jiang XM, Dou ZH, Rakeman MA, Zhang ML, O'Donnell K, et al. Timing of vulnerability of the brain to iodine deficiency in endemic cretinism. N Engl J Med. (1994) 331:1739-44. doi: 10.1056/NEJM199412293312603

54. Thilly CH, Delange F, Lagasse R, Bourdoux P, Ramioul L, Berquist H, et al. Fetal hypothyroidism and maternal thyroid status in severe endemic goiter. $J$ Clin Endocrinol Metab. (1978) 47:354-60. doi: 10.1210/jcem-47-2-354

55. Mason JB, Deitchler M, Gilman A, Gillenwater K, Shuaib M, Hotchkiss $\mathrm{D}$, et al. Iodine fortification is related to increased weight-for-age and birthweight in children in Asia. Food Nutr Bull. (2002) 23:292-308. doi: $10.1177 / 156482650202300309$

56. Glinoer D, Delange F, Laboureur I, de Nayer P, Lejeune B, Kinthaert J, et al. Maternal and neonatal thyroid function at birth in an area of marginally low iodine intake. J Clin Endocrinol Metab. (1992) 75:800-5. doi: $10.1210 /$ jcem.75.3.1517370

57. DeLong GR, Leslie PW, Wang SH, Jiang XM, Zhang ML, Rakeman $\mathrm{M}$, et al. Effect on infant mortality of iodination of irrigation water in a severely iodine-deficient area of China. Lancet. (1997) 350:771-3. doi: 10.1016/S0140-6736(96)12365-5

58. Thilly C, Swennen B, Moreno-Reyes R. Maternal, fetal and juvenile hypothyroidism, birthweight and infant mortality in the etiopathogenesis of the IDD spectrum in Zaire and Malawi. In: Stanbury JB, editor. The Damaged Brain of Iodine Deficiency. New York, NY: Cognizant Communication Corporation (1994). p. 241-50.

59. Semba RD, de Pee S, Hess SY, Sun K, Sari M, Bloem MW. Child malnutrition and mortality among families not utilizing adequately iodized salt in Indonesia. Am J Clin Nutr. (2008) 87:438-44. doi: 10.1093/ajcn/87.2.438

60. Zimmermann MB. The role of iodine in human growth and development. Semin Cell Dev Biol. (2011) 22:645-52. doi: 10.1016/j.semcdb.2011.07.009

61. Pharoah P, Buttfield IH, Hetzel BS. Neurological damage to the fetus resulting from severe iodine deficiency during pregnancy. Int J Epidemiol. (2012) 41:589-92. doi: 10.1093/ije/dys070
62. McCarrison R. Observations on Endemic Cretinism in the Chitral and Gilgit Valleys. Proc R Soc Med. (1909) 2:1-36. doi: 10.1177/0035915709002 00601

63. Pretell EA, Palacios P, Tello L. Iodine deficiency and the maternal/fetal relationship. In: Stanbury JB, editor. Endemic Goiter and Cretinism: Continuing Threats to World Health. Washington, DC: PAHO (1974). p. $143-55$.

64. Fierro-Benitez R, Cazar R, Stanbury JB, Rodriguez P, Garces F, Fierro-Renoy $\mathrm{F}$, et al. Effects on school children of prophylaxis of mothers with iodized oil in an area of iodine deficiency. J Endocrinol Invest. (1988) 11:327-35. doi: 10.1007/BF03349050

65. Boyages SC, Halpern JP, Maberly GF, Eastman CJ, Morris J, Collins J, et al. A comparative study of neurological and myxedematous endemic cretinism in western China. J Clin Endocrinol Metab. (1988) 67:1262-71. doi: 10.1210/jcem-67-6-1262

66. Halpern JP, Boyages SC, Maberly GF, Collins JK, Eastman CJ, Morris JG. The neurology of endemic cretinism. A study of two endemias. Brain. (1991) 114(Pt 2):825-41. doi: 10.1093/brain/114.2.825

67. O’Donnell KJ, Rakeman MA, Zhi-Hong D, Xue-Yi C, Mei ZY, DeLong N, et al. Effects of iodine supplementation during pregnancy on child growth and development at school age. Dev Med Child Neurol. (2002) 44:76-81. doi: 10.1017/S0012162201001712

68. Qian M, Wang D, Watkins WE, Gebski V, Yan YQ, Li M, et al. The effects of iodine on intelligence in children: a meta-analysis of studies conducted in China. Asia Pac J Clin Nutr. (2005) 14:32-42.

69. Boyages SC, Collins JK, Maberly GF, Jupp JJ, Morris J, Eastman CJ. Iodine deficiency impairs intellectual and neuromotor development in apparently-normal persons. A study of rural inhabitants of north-central China. Med J Aust. (1989) 150:676-82. doi: 10.5694/j.1326-5377.1989. tb136760.x

70. Eastman CJ, Ma G, Li M. Optimal assessment and quantification of iodine nutrition in pregnancy and lactation: laboratory and clinical methods, controversies and future directions. Nutrients. (2019) 11:2378. doi: $10.3390 /$ nu1 1102378

71. Bouhouch RR, Bouhouch S, Cherkaoui M, Aboussad A, Stinca S, Haldimann M, et al. Direct iodine supplementation of infants versus supplementation of their breastfeeding mothers: a double-blind, randomised, placebo-controlled trial. Lancet Diabetes Endocrinol. (2014) 2:197-209. doi: 10.1016/S2213-8587(13)70155-4

72. De Groot L, Abalovich M, Alexander EK, Amino N, Barbour L, Cobin RH, et al. Management of thyroid dysfunction during pregnancy and postpartum: an Endocrine Society clinical practice guideline. J Clin Endocrinol Metab. (2012) 97:2543-65. doi: 10.1210/jc.2011-2803

73. Alexander EK, Pearce EN, Brent GA, Brown RS, Chen H, Dosiou C, et al. 2017 Guidelines of the American Thyroid Association for the diagnosis and management of thyroid disease during pregnancy and the postpartum. Thyroid. (2017) 27:315-89. doi: 10.1089/thy.2016.0457

Disclaimer: The contents do not represent the views of the U.S. Department of Veterans Affairs or the United States Government.

Conflict of Interest: SM receives support by the Arkansas Biosciences Institute, the major research component of the Arkansas Tobacco Settlement Proceeds Act of 2000. This material is the result of work supported with resources and the use of facilities at the Central Arkansas Veterans Healthcare System, Little Rock, AR.

The remaining authors declare that the research was conducted in the absence of any commercial or financial relationships that could be construed as a potential conflict of interest.

Copyright (c) 2020 Toloza, Motahari and Maraka. This is an open-access article distributed under the terms of the Creative Commons Attribution License (CC BY). The use, distribution or reproduction in other forums is permitted, provided the original author(s) and the copyright owner(s) are credited and that the original publication in this journal is cited, in accordance with accepted academic practice. No use, distribution or reproduction is permitted which does not comply with these terms. 